\title{
Peran Inovasi dalam Total Quality Management dan Kinerja Organisasi
}

\author{
Marini ${ }^{1}$, Hesti Setiorini ${ }^{2}$, Rina Yuniarti $2^{*}$ \\ ${ }^{1}$ Program Studi Ekonomi Islam Fakultas Ekonomi dan Bisnis \\ 2Program Studi Akuntansi Fakultas Ekonomi dan Bisnis \\ Universitas Muhammadiyah Bengkulu \\ Jl. Bali Segara Kota Bengkulu 38119 Bengkulu
}

*Email: rinayuniarti@umb.ac.id

Naskah diterima 30 Agustus 2021, Revisi 20 September 2021, Terbit 29 Oktober 2021

\begin{abstract}
DOI: doi.org/10.21107/pamator.v14i2.12024

The purpose of this study was to determine the effect of Total Quality Management (TQM) on organizational performance mediated by innovation. This study used primary data in the form of a questionnaire to test the existing hypotheses and analyzed using the Structural Equation Model (SEM). The sample in the study amounted to 203 SMEs in Bengkulu City. Data were analyzed using descriptive statistical analysis using WarpPLS software version 6.0. The results showed that Total Quality Management has a significant positive effect on organizational performance meanwhile innovation does not mediate the effect of Total Quality Management on organizational performance.
\end{abstract}

Key words: organizational performance, management, structural equation model

\section{PENDAHULUAN}

Usaha Mikro Kecil dan Menengah (UMKM) merupakan sektor penting dalam menggerakkan roda perekonomian Indonesia yang perlu mendapat perhatian demi kondisi ekonomi Indonesia lebih baik. Kota Bengkulu merupakan provinsi yang terdiri dari 9 kecamatan, dimana perkembangan jumlah UMKM selalu mengalami peningkatan, akan tetapi kenyataannya masih banyak masalah yang dihadapi para pelaku UMKM dalam kegiatan operasional, keuangan, dan pengembangan kinerja, seperti kurangnya permodalan baik jumlah maupun sumbernya, rendahnya kualitas teknologi, kemampuan dan keterampilan, manajerial yang kurang dalam mengoperasikan usaha, produktivitas yang rendah, adanya beban regulasi di era globalisasi, serta lingkungan yang didorong oleh teknologi (Suci, 2017). Selain itu, kecenderungan konsumen di negara berkembang beranggapan bahwa produk lokal tidak sebagus produk impor (Wang et al., 2004; Nguyen et al., 2008). Hal ini menjadi permasalahan bagi produsen dalam negeri untuk bersaing dengan produk asing yang masuk di Indonesia. Dari penjelasan di atas bahwa tantangan para pelaku UMKM dalam menentukan strategi yang tepat agar produk yang dihasilkan memiliki daya saing dan keunggulan kompetitif untuk meningkatkan kinerja organisasi.

Bengkulu merupakan provinsi yang sektor perkoperasian dan UMKMnya memiliki peran penting dalam memajukan perekonomian daerah. Pembangunan ekonomi di Kota Bengkulu 60 persen ditopang dari sektor UMKM, dan 40 persen dari sektor lainnya (Anzori, 2019). Karakteristik keberadaan UMKM dianggap penting, karena potensinya dalam meningkatkan pertumbuhan lapangan pekerjaan, menghasilkan pendapatan, serta mengurangi kemiskinan (Tambunan, 2011). UMKM memiliki peran penting dan strategis dalam menciptakan pertumbuhan ekonomi. Akan tetapi kenyataannya masih banyak permasalahan yang dihadapi para pelaku UMKM dalam kegiatan operasional dan pengembangan kinerja, seperti kurangnya modal baik jumlah maupun sumbernya, rendahnya kualitas teknologi, kemampuan dan keterampilan manajerial yang kurang dalam mengoperasikan usaha, produktivitas yang rendah, adanya beban regulasi di era globalisasi, serta lingkungan yang didorong teknologi (OECD, 2000). Selain itu kualitas 
produk negara berkembang kurang bagus dibandingkan produk impor (Nguyen et al., 2008). Hal ini menjadi permasalahan bagi produsen dalam negeri untuk bersaing dengan produk asing yang masuk di Indonesia, sehingga menjadi tantangan bagi para pelaku UMKM dalam menentukan strategi yang tepat guna agar produk yang dihasilkan memiliki daya saing serta keunggulan kompetitif untuk meningkatkan kinerja organisasi.

Kinerja organisasi dapat ditingkatkan dengan mengimplementasikan praktik total quality management, yaitu sistem manajeman yang berfokus pada pelanggan dengan melibatkan semua level karyawan dalam melakukan peningkatan secara berkelanjutan (Mehmood et al., 2014; Qaswari et al., 2017). Antunes et al., (2018) kebanyakan peneliti beranggapan TQM sebagai pendekatan untuk meningkatkan efisiensi, fleksibilitas, dan daya saing bisnis dalam memenuhi kebutuhan pelanggan agar dapat memberikan manfaat operasional dan finansial bagi organisasi dan meningkatkan keunggulan kompetitif. Talib et al., (2010), TQM merupakan pendekatan kualitas dalam mengubah persepsi manajemen terkait globalisasi pasar, pertumbuhan ekonomi, kesadaran akan kualitas pelanggan dan perubahan ekonomi yang cepat. Kesadaran terhadap kualitas meningkat termotivasi oleh kualitas produk Jepang pada akhir abad-20 (O'Neill et al., 2016). Dean dan Bowen (1994), ada tiga prinsip umum pada kerangka TQM, yaitu fokus pelanggan, perbaikan berkelanjutan, dan Kerjasama. TQM berdampak perbaikan produk/jasa, menciptakan kepuasan pelanggan dan karyawan, serta meningkatkan kinerja keuangan, daya saing, dan produktivitas melalui pengurangan biaya (Parvadavardini et al., 2016; Li et al., 2016). Jagoda dan Kiridena (2015), kinerja organisasi dicerminkan melalui kapasitas dan kemampuan sistem operasi untuk mendukung sumber kompetitif, seperti harga produk/layanan, kualitas produk, dan waktu pengiriman sesuai pilihan organisasi.

Qaswari et al., (2017); Singh et al., (2018), dan Shafiq et al., (2019), menunjukkan bahwa implementasi TQM dapat meningkatkan kinerja organisasi. Semakin efektif pelaksanaan TQM maka kinerja organisasi dapat dicapai dengan maksimal. Sebaliknya Kober et al., (2012), menyatakan bahwa belum ada bukti bahwa TQM memiliki hubungan dengan kinerja keuangan, disebabkan kurangnya komitmen para pelaku usaha untuk melaskanakan implementasi TQM dalam menghadapi tekanan eksternal. TQM dapat memperluas metode dan teknik peningkatan kualitas untuk fungsi dan tingkat manajemen dalam suatu organisasi (Silva et al., 2014). Adanya penerapan TQM maka organisasi akan lebih fokus pada kualitas sebagai pedoman dan tolak ukur dari peningkatan kinerja, namun lingkungan yang semakin kompetitif membuat organisasi perlu untuk memperhatikan aspek kinerja yang lain, yaitu inovasi agar kinerja organisasi meningkat (Prajogo dan Sohal, 2004).

Inovasi memainkan peran penting dalam menyediakan produk/jasa yang unik, nilai lebih bagi organisasi, dan hambatan bagi pesaing (Antunes et al., 2017). Barney (1991), organisasi harus inovatif untuk bertahan hidup dan berkembang dalam lingkungan yang kompetitif dan cepat berubah, oleh karena inovasi menjadi penting yang harus dimiliki organisasi. Antunes dkk. (2017) mengungkapkan bahwa inovasi berpengaruh positif terhadap kinerja organisasi melalui posisi organisasi baik di pasar agar terciptanya keunggulan kompetitif (Al-Ansari et al., 2013; Khan dan Naeem, 2016). Adanya integrasi antara kualitas dan strategi inovasi untuk memenuhi permintaan pelanggan berupa produk berkualitas tinggi dengan harga kompetitif (Damanpour dan Aravind, 2012; Kajalo et al., 2016). Hamdoun et al., (2018), TQM tidak hanya memberikan dasar penting untuk memperbaiki inovasi, tetapi sebagai katalis bagi proses inovasi sehingga implementasi TQM pada organisasi dapat menciptakan lingkungan yang mendorong inovasi. Organisasi yang menerapkan TQM dianggap lebih inovatif daripada organisasi yang tidak menerapkan praktik tersebut (Prajogo dan Suhal, 2006). Implementasi TQM mendorong organisasi 
untuk berinovasi dan meningkatkan hubungan baik dengan pemasok maupun pelanggan.

Peneliti telah melakukan observasi awal selama kurang lebih tiga minggu, pada beberapa UMKM yang ada di kota Bengkulu. Peneliti memperoleh data bahwa jumlah UMKM yang ada di kota Bengkulu (Kecamatan Gading Cempaka, Kecamatan Kampung Melayu, Kecamatan Muara Bangkahulu, Kecamatan Ratu Agung, Kecamatan Ratu Samban, Kecamatan Selebar, Kecamatan Singaran Pati, Kecamatan Sungai Serut, dan Kecamatan Teluk Segara). Adapun jumlah UMKM pada masing-masing kecamatan di Kota Bengkulu adalah: Gading Cempaka 855, Kampung Melayu 680 UMKM, Muara Bangkahulu 419 UMKM, Ratu Agung 405 UMKM, Ratu Samban 882 UMKM, Selebar 400 UMKM, Singaran Pati 250 UMKM, Sungai Serut 275 UMKM, dan Teluk Segara 306 UMKM.

Berdasarkan uraian di atas masih terdapat hasil penelitian yang belum konsisten dan fenomena yang ada memotivasi peneliti menguji kembali yaitu TQM terhadap kinerja organisas untuk itu peneliti mencoba meneliti kembali dengan menambahkan variabel inovasi yang akan memediasi pengaruh TQM terhadap kinerja organisasi. Tujuan penelitian ini untuk mengetahui pengaruh TQM terhadap kinerja organisasi dimediasi oleh inovasi.

\section{METODOLOGI}

Penelitian yang digunakan adalah penelitian kuantitatif. Variabel independent dalam penelitian ini adalah TQM diukur menggunakan skala likert mulai dari 1 (sangat tidak setuju) sampai poin 5 (sangat setuju) dengan 21 butir pertanyaan. Variabel dependen dalam penelitian ini adalah kinerja organisasi diukur dengan skala likert poin 1 sampai poin 5 dari 5 butir pertanyaan. Variabel mediasi yang digunakan adalah inovasi diukur dengan skala likert poin 1 sampai poin 5 dari 10 butir pertanyaan (Qaswari et al., 2017; Honarpur et al., 2017).

Jenis data yang digunakan dalam penelitian ini adalah data primer berupa kuesioner yang dibagikan kepada pelaku UMKM kota Bengkulu. Populasi dalam penelitian ini adalah UMKM yang ada di Kota Bengkulu. Sampel merupakan bagian dari jumlah yang dimiliki oleh populasi (Anshori dan Iswati, 2017). Pengambilan sampel dalam penelitian ini menggunakan nonprobability sampling. Teknik pengambilan sampel menggunakan teknik convenience sampling. Teknik analisis data dalam penelitian ini menggunakan software WarpPLS versi 6.0

\section{HASIL PEMBAHASAN}

\section{Deskripsi Jawaban Responden}

Berdasarkan Tabel 1 diketahui bahwa rata-rata jawaban responden pada variabel TQM, Inovasi dan Kinerja Organisasi secara keseluruhan sebesar 4,042; 4,057 dan 4,002 dengan katagori setuju/tinggi. Hal ini menunjukkan bahwa mayoritas responden memiliki TQM, Inovasi dan Kinerja Organisasi yang baik.

Tabel 1. Kategori Rata-Rata Jawaban Responden

\begin{tabular}{ccc}
\hline Variabel & Mean & Kategori \\
\hline TQM & 4,042 & $\mathrm{~S} / \mathrm{T}$ \\
Inovasi & 4,057 & $\mathrm{~S} / \mathrm{T}$ \\
Kinerja & 4,002 & $\mathrm{~S} / \mathrm{T}$ \\
Organisasi & & \\
\hline
\end{tabular}

\section{Uji Validitas dan Reliabilitas Variabel}

Uji validitas dalam penelitian ini dengan menggunakan convergent validity dan discriminant validity. Convergent validity diukur menggunakan nilai Average Variance Extracted (AVE) yang harus lebih besar dari 0,50 atau memiliki $p$-value lebih kecil dari taraf signifikansi $<0,05$ (Sholihan dan Ratmono, 2014).

Tabel 2. Hasil Pengukuran Convergent Validity

\begin{tabular}{cc}
\hline Variabel & Nilai AVE \\
\hline TQM & 0,505 \\
Inovasi & 0,572 \\
Kinerja Organisasi & 0,741 \\
\hline
\end{tabular}

Discriminant validity diukur dengan membandingkan nilai Square Root Average Variance Extracted (AVE) setiap konstruk dengan korelasi antar konstruk lainnya dalam model yang ada pada kolom diagonal dan diberi tanda kurung, yang harus lebih tinggi dari korelasi antar variabel laten pada kolom yang sama (Sholihin dan Ratmono, 2014). Nilai AVE dan discriminant validity dalam 
penelitian ini dapat disajikan pada Tabel 2 dan Tabel 3.

Tabel 3. Hasil Pengukuran Discriminant Validity

\begin{tabular}{cccc}
\hline Variabel & TQM & Inovasi & $\begin{array}{c}\text { Kinerja } \\
\text { Organisasi }\end{array}$ \\
\hline TQM & $\mathbf{( 0 , 7 2 2 )}$ & 0,050 & 0,067 \\
Inovasi & 0,050 & $\mathbf{( 0 , 8 1 5 )}$ & 0,606 \\
Kinerja & 0,067 & $\mathbf{0 , 6 0 6}$ & $\mathbf{( 0 , 8 6 1 )}$ \\
Organisasi & & & \\
\hline
\end{tabular}

Berdasarkan Tabel 2 dan Tabel 3 diketahui bahwa uji convergent validity dan discriminant validity telah memiliki nilai yang memenuhi. Dari hasil tersebut disimpulkan bahwa seluruh variabel adalah valid dan dapat memberikan keyakinan. Langkah berikutnya dilakukan pengujian reliabilitas terhadap seluruh variabel yang digunakan dalam penelitian ini. Reliabilitas diuji dengan menggunakan koefisien composite reliability dan cronbach's alpha bernilai diatas 0,70 (Sholihin dan Ratmono, 2014). Hasil pengukuran composite reliability dan cronbach's alpha disajikan pada Tabel 4 berikut ini:

Tabel 4. Hasil Pengukuran Composite Reliability dan Cronbach's Alpha

\begin{tabular}{ccc}
\hline Variabel & $\begin{array}{c}\text { Composite } \\
\text { Reliability }\end{array}$ & $\begin{array}{c}\text { Cronbach's } \\
\text { Alpha }\end{array}$ \\
\hline TQM & 0,929 & 0,917 \\
Inovasi & 0,866 & 0,801 \\
Kinerja & 0,934 & 0,909 \\
Organisasi & & \\
\hline
\end{tabular}

Berdasarkan Tabel 4 di atas menunjukkan bahwa semua variabel memiliki nilai composite reliability dan cronbach's alpha lebih besar dari 0,70, disimpulkan bahwa seluruh variabel dalam penelitian ini adalah reliabel dan dapat diandalkan untuk digunakan dalam uji analisis lebih lanjut.

\section{Uii Inner Model}

Pengujian inner model dilakukan untuk menguji pengaruh antar variabel dalam penelitian ini dengan menggunakan nilai adjusted $\mathrm{R}^{2}$. Hasil uji inner model disajikan pada Tabel 5 berikut ini:

Tabel 5. Hasil Pengujian Inner Model

\begin{tabular}{ccc}
\hline Variabel & Adjusted $\boldsymbol{R}^{2}$ & $\begin{array}{c}\text { Nilai Q- } \\
\text { square } \\
\left(\mathbf{Q}^{2}\right)\end{array}$ \\
\hline $\begin{array}{c}\text { Kinerja } \\
\text { Organisasi } \\
\text { Inovasi }\end{array}$ & 0,377 & 0,405 \\
\hline
\end{tabular}

Berdasarkan Tabel 5, nilai Adjusted $\mathrm{R}^{2}$ kinerja organisasi sebesar $0,377(37,7 \%)$, ini menunjukkan bahwa kinerja organisasi dapat diprediksi oleh TQM dan inovasi sebesar $37,7 \%$ dan sisanya $62,3 \%$ dipengaruhi oleh variabel lain yang tidak dimasukkan dalam penelitian ini. Variabel inovasi memiliki nilai Adjusted $\mathrm{R}^{2}$ sebesar 0,063 (6,3\%) diartikan variabel inovasi dapat diprediksi oleh variabel TQM sebesar 6,3\% dan sisanya 34,1 dipengaruhi variabel lain yang tidak ada dalam penelitian ini. Nilai $Q^{2}$ disimpulkan bahwa variabel bebas dalam penelitian ini memiliki validitas prediktif baik, karena nilainya lebih besar dari nol.

\section{Uji Model Fit}

Penelitian ini menggunakan empat ukuran model fit, diantaranya average path coefficient (APC), average $R$-square (ARS), average adjusted $R$-square (AARS), dan average block variance inflation factor (AVIF). Nilai APC, ARS dan AARS digunakan untuk mengukur rata-rata nilai koefisien jalur yang diukur berdasarkan $p$-value maksimal $\leq$ 0,10 . AVIF digunakan untuk menguji masalah collinearity didalam model PLS dengan nilai yang direkomendasikan adalah $\leq 3,3$ (Ghozali dan Latan, 2015). Hasil uji model fit disajikan pada Tabel 6 berikut ini:

Tabel 6. Hasil Uji Model Fit

\begin{tabular}{ll}
\hline Average Path Coefficient (APC) & $0,290: \mathrm{p} \leq 0,001$ \\
Average R-Square (ARS) & $0,268: \mathrm{p} \leq 0,001$ \\
Average Adjusted R-Square (AARS) & $0,260: \mathrm{p} \leq 0,001$ \\
Dan Average Block Variance Inflation & 1,111 \\
Factor (AVIF) &
\end{tabular}

Berdasarkan Tabel 6, menunjukkan bahwa model dalam penelitian ini dinyatakan fit, APC, ARS, dan AARS nilai $p$-value $\leq 0,1$. Nilai AVIF $\leq 3,3$ disimpulkan bahwa tidak ada masalah multicollinearity antara indikator dan variabel yang digunakan.

\section{Uji Hipotesis}

Penelitian ini memiliki dua hipotesis yang terdiri dari pengujian langsung dan pengujian tidak langsung dengan menggunakan variabel mediasi. Adapun hasil pengujian hipotesis disajikan pada Tabel 7 berikut ini: 
Tabel 7. Pengujian Hipotesis

\begin{tabular}{|c|c|c|c|c|c|c|c|c|}
\hline \multicolumn{9}{|c|}{ Pengaruh Langsung } \\
\hline \multicolumn{2}{|c|}{ Hipotesis } & \multicolumn{2}{|c|}{$\begin{array}{l}\text { Variabel } \\
\text { Independen }\end{array}$} & \multicolumn{2}{|c|}{$\begin{array}{l}\text { Variabel } \\
\text { Dependen }\end{array}$} & $\beta$ value & $\rho$-value & Kesimpulan \\
\hline \multicolumn{2}{|l|}{$\mathrm{H} 1$} & \multicolumn{2}{|l|}{ TQM } & \multicolumn{2}{|c|}{ Kinerja Bisnis } & 0,22 & $<0.01$ & Diterima \\
\hline \multicolumn{9}{|c|}{ Pengaruh Tidak Langsung } \\
\hline \multirow{2}{*}{\multicolumn{2}{|c|}{$\begin{array}{l}\text { Pengaruh } \\
\text { Langsung } \\
\text { TQM - Kinerja } \\
\text { Organisasi }\end{array}$}} & \multicolumn{4}{|c|}{ Pengaruh Tidak Langsung } & \multirow{2}{*}{\multicolumn{2}{|c|}{$\begin{array}{l}\text { Perubahan } \beta \text { value dan } p \text { - } \\
\text { value }\end{array}$}} & Kesimpulan \\
\hline & & \multicolumn{2}{|c|}{ TQM - Inovasi } & \multicolumn{2}{|c|}{$\begin{array}{l}\text { Inovasi - Kinerja } \\
\text { Organisasi }\end{array}$} & & & \\
\hline$\beta$ & $\rho$ & $\beta$ & $\rho$ & $\beta$ & $\rho$ & & & \\
\hline$-0,08$ & 0,11 & $-0,17$ & $<0,01$ & 0,58 & $<0.001$ & $\begin{array}{l}\text { TQM - K } \\
\text { Menurun } \\
\text { signifikar }\end{array}$ & $\begin{array}{l}\text { a Organisasi } \\
\text { dan tidak }\end{array}$ & $\begin{array}{l}\mathrm{H} 2 \text { : indikasi full } \\
\text { mediation }\end{array}$ \\
\hline \multicolumn{6}{|c|}{ Nilai $p$ - value Indirect effect for path with 2 segment } & 0,139 & & $\begin{array}{l}\text { Tidak terdapat efek } \\
\text { mediasi }\end{array}$ \\
\hline
\end{tabular}

Tabel 7 menunjukkan bahwa pengaruh langsung sebelum dimasukkan variabel mediasi diketahui bahwa TQM memiliki pengaruh positif signifikan terhadap kinerja organisasi. Hal ini dilihat dari $p$-value yang memiliki nilai $<0,01$. Ini menunjukkan bahwa implementasi TQM akan meningkatkan kinerja organisasi. Hipotesis pertama $(\mathrm{H} 1)$ dalam penelitian ini diterima. Inovasi merupakan variabel yang tidak memediasi pengaruh TQM terhadap kinerja organisasi. Hal tersebut dapat dilihat berdasarkan nilai $p$ value of indirect effect with 2 segment TQM terhadap kinerja organisasi yang memiliki nilai $>0,1$ yaitu sebesar 0,139 , meskipun berdasarkan analisis koefisien jalur terdapat indikasi bahwa inovasi memediasi pengaruh TQM terhadap kinerja organisasi namun tidak didukung dengan hasil $p$-value of indirect effect with 2 segment memiliki nilai yang tidak signifikan disimpulkan tidak terdapat efek mediasi inovasi. Dengan demikian hipotesis kedua (H2) dalam penelitian ini ditolak.

Uji hipotesis 1 memperlihatkan hasil hipotesa dapat diterima. Implementasi TQM dapat meningkatkan kinerja organisasi. Hasil penelitian ini mendukung teori resourced based view bahwa sumber daya yang ada harus menciptkan nilai yang tidak dapat dilakukan oleh kompetitor demi memperoleh keunggulan kompetitif (Barney, 1991). Implementasi TQM bagi para pelaku UMKM jika dilakukan dengan tepat maka akan dapat meningkatkan kinerja organisasi. Hasil penelitian ini mendukung penelitian yang dilakukan oleh Qaswari et al., (2017) yang menyatakan bahwa jika TQM dilakukan dengan efektif maka organisasi memperoleh tingkat kinerja yang maksimal (Shafiq et al.,
2017). TQM yang dilakukan oleh UMKM Kota Bengkulu merupakan strategi manajemen mutu yang berfokus pada pelanggan dengan melibatkan semua anggota organisasi/ perusahaan, baik dari tingkat operasional hingga eksekutif yang saling bekerja sama dengan tujuan untuk mendapatkan keunggulan kompetitif disbanding pesaing dengan cara melakukan peningkatan atau perbaikan secara terus menerus.

Berdasarkan pengujian statistik terlihat bahwa inovasi tidak memediasi pengaruh TQM terhadap kinerja organisasi pada UMKM Kota Bengkulu, disimpulkan inovasi bukan variabel mediasi. Hasil penelitian diketahui implementasi TQM tidak sejalan dengan inovasi, karena penekanan pada efisiensi perbaikan berkelanjutan pada akhirnya akan meminimalkan dan menghilangkan ketersediaan sumber daya yang diperlukan untuk melakukan inovasi.

Ditolaknya inovasi sebagai variabel mediasi kemungkinan disebabkan para pelaku UMKM Kota Bengkulu sangat berhatihati dalam melakukan inovasi karena biaya yang akan dikeluarkan sangat tinggi dan membatasi peluang untuk berinovasi, sehingga berdampak para pelaku UMKM merasa nyaman atas produk yang dikembangkan saat. Ini mengindikasikan bahwa para pelaku UMKM tidak akan bertahan lama di pasar jika tidak melakukan inovasi dan tidak memberikan konstibusi positif terhadap kinerja organisasi. Hasil penelitian ini tidak sejalan dengan penelitian yang dilakukan oleh Khan dan Naeem (2016) bahwa inovasi dapat memediasi pengaruh TQM terhadap kinerja organisasi. 


\section{KESIMPULAN}

Implementasi TQM berpengaruh positif signifikan terhadap kinerja organisasi. Implementasi TQM bagi para pelaku UMKM jika dilakukan dengan tepat maka akan dapat meningkatkan kinerja organisasi. Inovasi tidak memediasi pengaruh implementasi TQM terhadap kinerja organisasi. Hal ini disebabkan karena implementasi TQM dapat membuat para pelaku UMKM lebih berhatihati dalam melakukan inovasi dan bergantung pada elemen TQM yang digunakan, sehingga kinerja organisasi tidak mengalami peningkatan.

Keterbatasan penelitian ini adalah terdapat indikator yang tidak valid dalam variabel TQM, inovasi dan kinerja organisasi, sehingga perlu pengkajian ulang atas penggunaan indikator-indikator tersebut dalam mengukur ketiga variabel atau dilakukan perbaikan kalimat pernyataan poin agar mudah dipahami oleh responden.

Saran untuk penelitian yang akan datang yaitu: (1) mengkaji ulang indikator-indikator pernyataan yang tidak valid; (2) memperluas subjek penelitian, tidak hanya terbatas pada UMKM yang ada di Kota Bengkulu dan (3) memperbanyak variabel penelitian

\section{UCAPAN TERIMA KASIH}

Penulis mengucapkan terima kasih kepada:

1. Kementrian riset, teknologi dan pendidikan tinggi atas bantuan dana yang diberikan dalam penelitian dosen pemula

2. Lembaga Penelitian dan Pengabdian Masyarakat Universitas Muhammadiyah Bengkulu atas segala dukungannya

3. Dinas Koperasi dan PKM yang telah memberikan data UMKM yang ada di Kota Bengkulu

\section{DAFTAR PUSTAKA}

Al-Ansari, Y., Pervan, S., \& Xu, J. (2013). Innovation and business performance of SMEs: The case of Dubai. Education, Business and Society: Contemporary Middle Eastern Issues, 6(3), 162-180. https://doi.org/10.1108/EBS-04-2013$\underline{0012}$

Anshori, M., \& Iswati, S. (2017). Metodologi Penelitian Kuantitatif. Surabaya: Airlangga University Press (AUP).
Antunes, M.G., Quiros, J.T., \& Fernandes, R. (2017). The Relationship between Innovation and Total Quality Management and The Innovation Effects on Organizational Performance. International Journal of Quality and Reliability Management.

https://doi.org/doi.org/10.1108/lJQRM-022016-0025

Anzori. (2019). Konstribusi UMKM pada Pertumbuhan Ekonomi Capai 60\%. https://www.tuntasonline.com/2019/11/15/ kontribusi-umkm-pada-pertumbuhanekonomi-capai-60/. Diakses 23 Januari 2021.

Barney. (1991). Firm Resouces and Sustained Competitive Advantage. Journal of Management, 17(1), 99120.https://doi.org/10.1170/01492063910 1700108

Damanpour, F., \& Aravind, D. (2012). Managerial Innovation: Conceptions Processes, and Antecedents. Management and Organization Review, 8(2), 423-454. http://doi.org/10.1111/j.1740-

8784.2011.00233.x

Dean, J, W., \& Bowen, D.E. (1994). Management Theory and Total Quality Improving Research and Practice Through Theory Development. Academy of Management Review, 19(3), 392-418. https://doi.org/10.5465/amr.1994.941227 1803

Ghozali, \& Latan, H. (2015). Partial Least Square: Konsep, Teknik, \& Aplikasi Menggunakan Program SmartPLS 3.0. Semarang: Universitas Diponegoro

Hamdoun, M., Chiappetta Jabbaour, C, J., \& Ben Othman, H. (2018). Knowledge Transfer and Organizational Innovation: Impacts of Quality and Environmental Management. Journal of Cleaner Production, 193, 759-770. https://doi.org/10.1016/j.jclepro.2018.05.0 31

Honarpur, A., Jusoh, A., \& Md Nor, K. (2017). Total Quality Management, Knowledge Management, and Innovation: An Empirical Study in R\&D Units. Total Quality Management and Business 
Excellence, $\quad 29(78), \quad$ 798-816. https://doi.org/10.1080/14783363.2016.12 38760

Jagoda, K., \& Kiridena, S. (2015). Operations Strategy Processes and Performance. Journal of Manufacturing Technology Management, 26 (2), 261-279. https://doi.org/10.1108/jmtm-10-20130156

Kajalo, S., Rajala, A., \& Tuominem, M. (2016). The Impact of Market-Based Assets on Innovativeness and Business Performance. International Journal of Business Innovation and Research, 11(4), 576-584.

https://doi.org/10.1504/ijbir.2016.079511

Khan, B.A., \& Naeem, H. (2016). Measuring The Impact of Soft and Hard Quality Practices on Service Innovation and Organizational Performance. Total Quality Management and Business Excellence, 29(11-12), 1402-1426. https://doi.org/10.1080/14783363.2016.12 63543

Kober, R., Subraamanniam, T., \& Watson, J. (2012). The Impact of Total Quality Management Adoption on Small and Medium Enterprises' Financial Performance. Accounting and Finance, 52(2),

https://doi.org/10.1111/j.1467-

629X.2011.00402.x

Li, D.,Zhao, Y., Zhang, L., Chen, X., \& Cao, C. (2018). Impact of Quality Management on Green Innovation. Journal of Cleaner Production, 170, 462-470. https://doi.org/10.1016/j.jclepro.2017.09.1 5

Mehmood, S., Qadeer, F., \& Ahmad, A. (2014). Relationship between TQM Dimensions and Organizational Performance. Pakistan Journal of Commerce and Social Science, 8(3), 662679

Nguyen, T,D., Nguyen, T.T.M., \& Barret, N.J. (2008). Consumer Ethnocentrism Cultural Sensitivity, and Integration to Purchase Local Products- Evidence from Vietnam. Journal of Consumer Behaviour, 7(1), 88100.doi.10.1002/cb.238.
OECD. (2000). Small and Medium-sized Enterprises: Local Strenght, Global Research.

O'Neill, P., Sohal, A., \& Teng, C.W. (2016). Quality Management Approaches and Their Impact On Firms' Financial Performance - An Australian Study. International Journal of Production Economics, 171, 381-393. https://doi.org/10.1016/j.ijpe.2015.07.015

Parvadavardini, S., Vivek, N., \& Devadasan, S.R. (2016). Impact of Quality Management Practices on Quality Performance and Financial Performance: Evidence from Indian Manufacturing Companies. Total Quality Management and Business Excellence, 27(5-6), 507530.

https://doi.org/10.1080/14783363.2015.10 15411

Prajogo, D, I., \& Sohal, A.S. (2004). The Multdimensionality of TQM Practices in Determining Quality and Innovation Performance - An Empirical Examination. Technovation, 24(6), 443-453. https://doi.org/10.1016/S01664972(02)00122-0

Prajogo, D, I., \& Sohal, A.S. (2006). The Integration of TQM and Technology R\&D Management in Determining Quality and Innovation Performance. Omega, 34(3), 296-312.

https://doi.org/10.1016/j.omega.2004.11.0 04

Qasrawi, B.T., Almahamid, S.M., \& Qasrawi, S.T. (2017). The Impact of TQM Practices and KM Process on Organizational Performance. International Journal of Quality \& Reliability Management, 34(7), 1034-1055.

https://doi.org/10.1108/136732706106794 35

Shafiq, M., Lasrado, F., \& Hafeez, K. (2017). The Effect of TQM on Organizational Performance: Empirical Evidence fro Textile Sector of A Developing Country Using SEM. Total Quality Management and Business Excellence, 30(1-2), 31-52.

Singh, V., Kumar, A., \& Singh, T. (2018). Impact of TQM on Organizational Performance: The Case of Indian 
Manufacturing and Service Industry. Operations Research Perspective, 5, 199217.

https://doi.org/10/1016/j.prp.2018.07.004

Sholihin, M., \& Ratmono, D. (2014). Analisis SEM-PLS dengan WarpPLS 3.0 untuk Hubungan Nonlinear dalam Penelitian Sosial \& Bisnis. Yogyakarta: Penerbit ANDI

Suci, Y.R. (2017). Perkembangan UMKM (Usaha Mikro Kecil dan Menengah) Di Indonesia. Jurnal IImiah Fakultas Ekonomi, 6(1), 51-58
Talib, F., Rahman, Z., \& Qureshi, M.N. (2010). The Relationship between Total Quality Management and Quality Performance in The Service Industry: A Theoretical Model. MultiCraft International Journal of Business, Management and Social Sciences, 1(1),113-128

Wang, Cheng Lu, \& Chen, Z.X. (2004). Consumer Ethnocentrism and Willingness to Buy Domestic Product in A Developing Country Setting: Testing Moderating Effects. Journal of Consumer Marketing, 2(6), 391-400. https://doi.org/10.1108/073637604105586 63 